\section{Original Article}

Dr. Hasibul Hasan

BDS, MS

Assistant Professor Dept. of Conservative Dentistry \& Endodontics Pioneer Dental College, Dhaka.

Dr. Kazi Hasinur Rahman BDS, MS

Assistant Professor Dept. of Prosthodontics Pioneer Dental College, Dhaka.

Dr. Shamim Sultana BDS, PhD

Assistant Professor \& Head Dept.of Oral Anatomy \& Physiology

Pioneer Dental College, Dhaka

Dr. Md. Mahfuzur Rahman BDS, MS Associate Professor Dept. of Conservative Dentistry \& Endodontics City Dental College, Dhaka.

Prof. Dr. Md. Shamsul Alam BDS, DCD (USSR), FADI (USA) Professor \& Chairman Dept. of Conservative Dentistry \& Endodontics Dean Faculty of Dentistry, BSMMU, Dhaka.

\title{
A vivo study on dowel crown with more aesthetic and healthy Fiber Reinforced Composite post system
}

\section{Abstract :}

Statement of problem. Patients having grossly carious teeth with broken down crown are needed to be restored with post \& core after endodontic treatment. Root canal posts are widely used \& come in a variety of metals \& forms. However, cast metal posts, although better than other post \& core systems, still possess some disadvantages, like corrosion $\&$ discoloration at the gingival margin of the treated tooth $\&$ cause aesthetic problem. These problems are overcome with the recently introduced post $\&$ core material. The fiber reinforced composite post $\&$ core material is a superior $\&$ efficient alternative to cast post. Purpose. The purpose of this study was to investigate the success of fiber reinforced composite post \& core system over conventional metallic system in regards of corrosion \& discoloration resistance with periodontal condition on post treated tooth . Materials $\&$ Methods. This was a prospective study, conducted in the department of Conservative Dentistry \& Endodontics, B.S.M.M.U. 40 patients were purposively selected who attended in this department with grossly carious teeth with badly broken crown without apical infection as the subject of this study \& divided in two groups. 20 patients were included in group A as case subjects \& they were treated with fiber reinforced post \& core system. 20 patients were included in group B as control subjects. They were treated with conventional cast metallic post \& core system. After twelve months, recorded data were compiled on a master chart and statistically analyzed. Chisquare test and t-test (unpaired) were done for statistical significance $(\mathrm{P}<0.05)$. Results. Very highly significant difference $(\mathrm{p}<.001)$ was observed between the groups in the evaluation of resistance to corrosion \& discoloration, there were no significant difference $(\mathrm{p}>.05)$ in periodontal evaluation Conclusion. This study revealed that fiber reinforced composite post \& core system can overcome the problems faced by the metallic post $\&$ core system. So it can be concluded that fiber reinforced composite post $\&$ core system can be a promising alternative in comparison to metallic post \& core system.

\section{Introduction:}

Grossly carious teeth with badly broken crown are often seen in our daily dental practice. Most of these patients are willing to conserve their teeth by any means. It is also the challenge of the endodontists to preserve those badly broken teeth rather than extraction. But unfortunately in many cases often not much tooth structure is left in the coronal portion to hang the crown. In this reason we need to do a special kind of filling into the root of tooth after root canal treatment, is called post. That is firmly embedded in the remaining portion of the teeth and is not dislodged later when it is prepared as a core for retaining the crown. Preparation of a crown by using the retention and stability from the post and core is called dowel crown. 
Different types of available procedures for dowel fabrication are followed world wide but not all the procedures ensure sound and prolong prognosis of a dowel crown with good esthetic and function. Longevity of a tooth restored with dowel crown depends on retention of post, resistance of root fracture and development of any apical lesion due to any microleakage. All these criteria's for good prognosis can be achieved by selecting a proper design of post with employing correct geometry and extension of ferrule. So, an appropriate post design is very essential for longevity of a tooth restored with dowel crown. Prior to begin the clinical procedure for a single crown or fixed partial denture, some important characteristics should be assessed for the fabrication of a post \& core. One of these characteristics is the selection of the type of posts. They may be cemented/bonded post or threaded posts. Cemented posts depend on their close proximity to prepared dentinal walls \& the cementing medium. Examples are custom cast posts \& cores \& a variety of prefabricated design. The prefabricated design includes parallel sided metal post, such as Para Post or different types of threaded posts. Examples of threaded posts are Kurer Post, Dentatus, Flexi Post etc. Recently, posts made of fiber reinforced composite polymers (Ribbond, Fiberkor Post System, C omposopost, Snow Post System) have been introduced. Esthetic version of these posts has a quartz exterior that makes the post tooth colored. Fiber reinforced posts are made of a woven polyethylene fiber system, that is coated with dentin bonding agent $\&$ packed into the canal, where it is then light polymerized in position. Therefore, although the custom cast post systems are still to be highly appreciated \& dependant systems in dowel crown, the recent advancement of the dowel system by using the fiber reinforced composite post \& core material have advantages in some of the desired criteria of dowel crown over the custom cast post.

\section{Technical procedure :}

Crown of tooth was prepared by removing residual caries, any weak restoration or thin unsupported enamel was removed. Remaining tooth was prepared as usual. A sub-gingival facial shoulder and lingual chamfer were placed. A 60 degree bevel was prepared around the occluso-axial line angle to create core ferrule for cast post. Pulp chamber was prepared by removing all filling material from the pulp chamber and cleaned the chamber.When composite post is used, undercuts \& irregularities in pulp chamber will help to retain the core material.
Undercuts in the pulp chamber were blocked out with filling material or eliminating by removing the tooth structure with out weakening the tooth.

Root canal preparation was done by a pesso-reamer to remove the root canal filling material from the root canal. Before removing the GP, the appropriate length of the post was calculated from radiograph and a rubber stop was placed perpendicular to the shaft of the pesso-reamer. The length and the diameter of canal preparation at least $2 / 3$ length of root and $1 / 3$ width of root respectively. A radiograph was taken to ensure proper length and width of the prepared canal. The canal is enlarged in size using the rotatory instrument that corresponds to the final dimension of the selected post. The post should fit passively in to the post space without substantial movement. At least the apical half of the post should fit closely to the preparation. The coronal half of the post may not fit as well because of root canal flaring. However, this lack of adaptation can be corrected when the core material is placed around the cemented post. Care must be taken not to remove more dentin at the apical extent of the post space than is necessary. Radiographic confirmation is important to ensure proper seating and length of the post. The incisal/occlusal end of the post is shortened, so it does not interfere with the opposing occlusion, but it must provide support and retention for the restorative core material. The post is cemented in to the root canal by using resin bonding procedure. Restorative material is then condensed around the post or bonded to the post and remaining tooth structure. A slight excess of material is placed and this is removed during crown preparation.After root canal preparation a custom made post can be fabricated from a direct procedure and an indirect procedure and invested for casting. After casting The post and core was inserted in to the canal with gentle pressure to check any interference before full seating, due to casting defect glass ionomer cement was used for cementation of post. The definite tooth preparation is then completed \& impression is made for crown.

\section{Results:}

Forty diagnosed subjects were included in this study. Out of 40 subjects 20 were designated as case, who were treated with fiber reinforced composite post \& core system, and 20 were designated as control, who were treated with conventional cast metal post \& core system. 
Table I: Distribution of patients by evaluation of Periodontal \& gingival condition of the abutment $(n=40)$

\begin{tabular}{|l|l|l|l|l|}
\hline Groups & $\begin{array}{l}\text { Grade-I } \\
\text { (number) }\end{array}$ & $\begin{array}{l}\text { Grade-II } \\
\text { (number) }\end{array}$ & $\begin{array}{l}\text { Chi- } \\
\text { square } \\
\text { value }\end{array}$ & P-value \\
\hline $\begin{array}{l}\text { Case } \\
\mathrm{n}=\mathbf{2 0}\end{array}$ & 12 & 8 & 0.102 & \multirow{2}{*0.05(\mathrm{ns})}{} \\
\hline $\begin{array}{l}\text { Control } \\
\mathrm{n}=\mathbf{2 0}\end{array}$ & 11 & 9 & & \\
\hline
\end{tabular}

Chi-square test was done as the test of significance, $p>0.05=$ not significant

In table I \& fig I, periodontal \& gingival condition of the abutments was evaluated. Case group had $12(60 \%)$, \& $8(40 \%)$ patients in grade I \& II, where as control group had $11(55 \%), \& 9(45 \%)$ patients in grade I \& II respectively. There were no patients in third or four grade in both groups \& there was not also any significant difference in between case \& control group.

Grade I - (Depth-0)-Normal depth of the sulcus-1$2 \mathrm{~mm}$.

Grade II - (Depth-1)-2-3mm sulcus depth

Grade III - (Depth-2)- 3-4 mm sulcus depth

Grade IV- (Depth-3)- Above 4mm sulcus depth

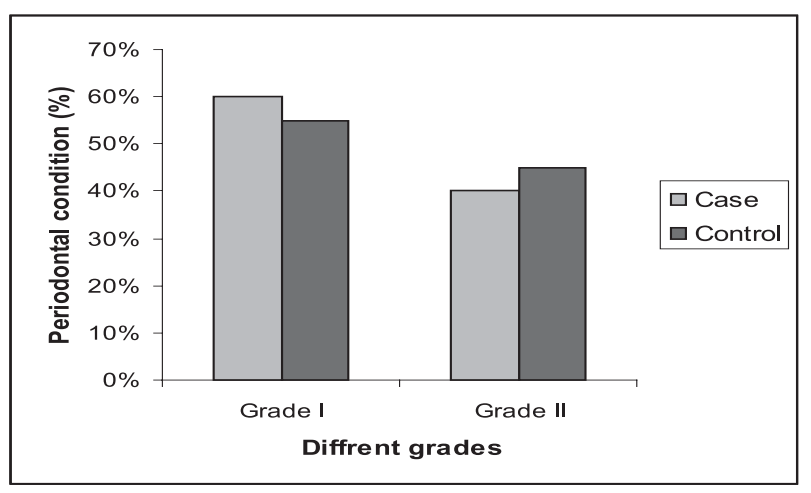

Fig I: Comparison of periodontal condition between groups

Table 11: Distribution of patients by evaluation of corrosion \& discoloration ( $\mathrm{n}=40)$

\begin{tabular}{|l|l|l|l|l|}
\hline Groups & $\begin{array}{l}\text { Grade-I } \\
\text { (number) }\end{array}$ & $\begin{array}{l}\text { Grade-II } \\
\text { (number) }\end{array}$ & $\begin{array}{l}\text { Chi- } \\
\text { square } \\
\text { value }\end{array}$ & P-value \\
\hline $\begin{array}{l}\text { Case } \\
\mathbf{n}=\mathbf{2 0}\end{array}$ & 20 & 0 & 10.08 & $<0.001$ (vhs) \\
\hline $\begin{array}{l}\text { Control } \\
\mathbf{n = 2 0}\end{array}$ & 10 & 10 & & \\
\hline
\end{tabular}

Chi-square test was done as the test of significance, ${ }^{*} p<.001=$ very highly significant
In 'corrosion \& discoloration', case \& control groups were evaluated with two grades in the table II \& fig II. Among the case group all (100\%) patients were found in grade I \& control group had 10(50\%), \& 10(50\%) patients in grade I \& II respectively, \& there was very highly significant difference in between case \& control group. $(p<.001)$

\section{Grade - I : Good}

(No corrosion and discoloration shown through the gum margin).

\section{Grade - II : Poor}

(Corrosion and discoloration shown through the gum margin).

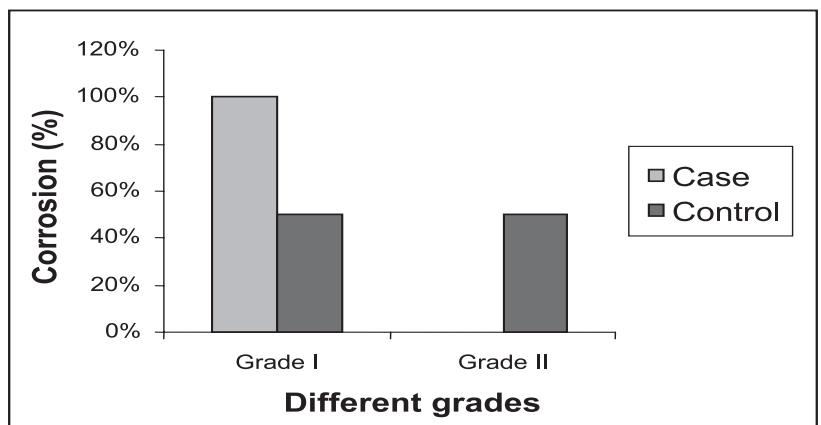

Fig II: Comparison of corrosion between groups

\section{Discussion:}

The study was conducted in the department of Conservative dentistry \& endodontics, Faculty of Dentistry, BSMMU, with purposive sampling based on the patients having grossly carious teeth with badly broken crown. These groups of patients are conventionally managed with cast or pre-fabricated metallic post \& core system. But the introduction of composite post \& core system in the late 80 s to early 90 s has changed the concept \& the success of the treatment. Margareta et al have described in their retrospective study on 236 patients done in the University of Karolinska that, the fiber reinforced composite post offers a resilient, highly retentive method with uninterrupted bonding between the tooth through the post \& core, \& has superior retention \& esthetic than metallic post. We tried with alternative \& newer concept of fiber reinforced composite post \& core system to restore the grossly carious teeth with extensively broken crown with good result. The age range of this study was 2248 years for case group \& 20-49 years for control group. The mean age of case \& control were $34.25 \pm 6.414 \& 34.45 \pm 6.909$ respectively \& there was no significant difference. The male \& female were randomly included in this study. Among cases 12 were male \& 8 were female. In the control group 11 were male \& 9 were female. There was no significant difference regarding the sex distribution between case \& control. 
After 12 month's assessment. The periodontal conditions such as plaque accumulation, gingival health, bleeding on probing \& pocket depth around the teeth with composite post $\&$ core system were similar to the teeth used as control. No patients, treated with composite post \& core system had any findings of corrosion \& discoloration at the gingival margin \& were proved to be esthetically highly satisfactory. On the other hand fifty percent of patients treated with cast metallic post \& core system developed corrosion \& discoloration at the gingival margin \& was esthetically unpleasant. The composipost system is a new concept for post \& core restoration on endodontically treated teeth. For optimal results the manufacturer's instruction must be followed carefully. When the system is used, a resin based cement is necessary. Resin cements establish a stronger bond to the dentin walls of the root canal after the removal of die smear layer \& application of dentin bonding agents $\&$ to the post itself thereby increasing the retention of the dowel.

\section{Conclusion:}

In the clinical follow-up studies a definition of success should be based on objective criteria. Results of fiber reinforced composite post over a period of one year were evaluated in a ptrospective study of radiographic, esthetic \& periodontal parameters. For the forty evaluated teeth, no tooth had to be extracted, no dislodgement of post \& crown was encountered. There was no radiographic change in the adaptation. No pronounced marginal bone resorption with a very negligible percentage of post \& root fracture. There were no differences between case $\&$ control group with respect of plaque accumulation, gingival health \& pocket probing depth. No patients, treated with composite post \& core system had any findings of corrosion \& discoloration at the gingival margin \& were proved to be esthetically highly satisfactory. On the other hand fifty percent of patients treated with cast metallic post \& core system developed corrosion \& discoloration at the gingival margin \& was esthetically unpleasant. Fiber reinforced composite post \& core system is a very recent addition to endodontic \& conservative dentistry worldwide. It is yet to be introduced in Bangladesh. From the above made conclusive follow up, it can be a popular, efficient \& promising alternative to cast metallic post \& core system \& can bring a newer scope in endodontic treatment.

\section{References :}

1. Gerald J, Ziebert. Restoration of endodontically treated teeth : Tylman's Theory and Practice of Fixed Prosthodontics. 8th ed; 1997. p. 407-416.

2. Stephen F, Rosentiel, Martin F, Land, Junhei, Fujimoto. Restoration of endodontically treated teeth : Contemporary Fixed Prosthodontics. 3rded. Indian reprint: Mosby;2002. p. 273.

3. Sirimai S, Riis DN, Moggano SM. An in vitro study of the fracture resistance $\&$ the incidence of vertical root fracture of pulpless teeth restored with six post $\&$ core systems.J.Prosthet Dent.1999; vol.81: p.262.

4. Margareta, Fredriksson, Johny, Asthack, Madeliene, Pamenius, Kristina, Srvidson. A retrospective study of 236 patients with reeth restored by carbon fiber reinforced epoxy resin post. J Prosthet Dent.1998; vol.5: p.22-39.

5. Isidor F, Odman P, Brond, Ltrn K. Intermittent loading of teeth restored using prefabricated carbon fiber posts. Int Prosthodont. 1996; vol.4: p.5-11.

6. Lacy AM. Adhesive restoration of a non-vital anterior tooth using a carbon fiber post \& all porcelain crown. Pract Periodontics Aesthetic Dent. 1995 ; vol.7: p.09. 